\title{
Online supervised versus workplace corrective exercises for upper crossed syndrome: a protocol for a randomized controlled trial
}

\author{
Zohreh Yaghoubitajani ${ }^{1}$, Mehdi Gheitasi ${ }^{1 *}$, Mohammad Bayattork ${ }^{2}$ and Lars Louis Andersen ${ }^{3,4}$
}

\begin{abstract}
Background and objective: Musculoskeletal disorders (MSDs) including upper crossed syndrome (UCS) are considered as the leading cause of work-related issues worldwide among office workers. Therefore, the present study aims to evaluate the effect of workplace-based versus online-supervised home-based corrective exercises among office workers with UCS.

Methods and design: To this end, 45 subjects within the age range of 30-45 years are randomly assigned to three groups in the present parallel-group, randomized control trial using a pretest-posttest design. These groups include the subjects who receive online-supervised exercise and workplace exercise containing three sessions of intervention for 8 weeks and the control group receives no intervention while performing routine activities. The primary outcome variables are neck-shoulder pain (NSP) and consequent sick leave due to NSP, followed by alignment, workability, and the surface electromyography of upper, middle, and lower trapezius (UT, MT, and LT), sternocleidomastoid (SCM), and serratus anterior (SA) as the secondary variables.

Discussion: The present study seeks to assess the effect of workplace versus online-supervised corrective exercise interventions among 45 office workers suffering from UCS. It is expected to improve and reduce the related symptoms including postural malalignment and imbalance muscles after 8 weeks of corrective exercises. If effective, the findings may lead to adherence and work performance among the office workers, and individuals subjected to UCS can use the benefits of an online-supervised intervention. In addition, the findings may be useful in different workplaces as the evidence for employers to benefit from the reduction in the related costs and side effects of work-related neck/shoulder disorders including work disability, productivity loss, time expense, social insurance, work absenteeism, and treatment costs. Finally, clinicians and corrective exercise therapists can consider it as a clinical based-evidence intervention for their further actions.
\end{abstract}

Trial registration: Iranian Registry of Clinical Trials IRCT20200729048249N1. Registered on 5 October 2020 (https:// en.irct.ir/user/trial/49992/view)

Keywords: Online corrective exercises, Workplace, Muscle activity, UCS, Pain, Workability

\footnotetext{
* Correspondence: m_gheitasi@sbu.ac.ir; mehdi.gheitasi@gmail.com

'Department of Health and Sports Rehabilitation, Faculty of Sports Science and Health, Shahid Beheshti University, Tehran, Iran

Full list of author information is available at the end of the article
}

(c) The Author(s). 2021 Open Access This article is licensed under a Creative Commons Attribution 4.0 International License, which permits use, sharing, adaptation, distribution and reproduction in any medium or format, as long as you give appropriate credit to the original author(s) and the source, provide a link to the Creative Commons licence, and indicate if changes were made. The images or other third party material in this article are included in the article's Creative Commons licence, unless indicated otherwise in a credit line to the material. If material is not included in the article's Creative Commons licence and your intended use is not permitted by statutory regulation or exceeds the permitted use, you will need to obtain permission directly from the copyright holder. To view a copy of this licence, visit http://creativecommons.org/licenses/by/4.0/ The Creative Commons Public Domain Dedication waiver (http://creativecommons.org/publicdomain/zero/1.0/) applies to the data made available in this article, unless otherwise stated in a credit line to the data. 


\section{Background}

Nowadays, sedentary work is considered predominant in various parts of the world due to the rapid development of technology and the new nature of work. The workers are exposed to prolonged static posture and repetitive upper limb movements $[1,2]$ and spend long periods in front of a computer or at a desk in a dorsiflexed position with rounded shoulders [3]. According to Page [4, 5], these prolonged postures may under-activate some muscles while over-activating other muscles leading to joint dysfunction known as "upper crossed syndrome" (UCS). In addition, specific postural changes due to the UCS may decrease glenohumeral stability causing elevated shoulders and scapulae winging. Accordingly, the levator scapula and upper trapezius require increasing activation in order to maintain glenohumeral centration to compensate for the loss of this stability [4-7]. All these alterations may be associated with work-related neck/ shoulder disorders (WNSDs) although the casualty of the association between computer use and pain is unknown [8].

As one of the main concerns of public health, WNSDs may be related to pain and impaired physical functions causing musculoskeletal complaints and affecting work performance among the office workers [9]. Further, WNSDs with annual prevalence rates of $27-48 \%$ influence the musculoskeletal system leading to numerous work-related disorders $[10,11]$. Regardless of the actual cause of pain, musculoskeletal pain in the neck and shoulders increase the risk of long-term sickness absence in white-collar workers [12]. The prevalence of this type of pain was reported relatively high in the neck and shoulders (45.8 and 40.1\%, respectively) in Iran [13]. Thus, different employees are at an increased risk of sickness absence. Regarding the major role of WNSDs in both employees and employers, as the most common reasons for work disability, sick leaves, and early retirement, it is considered as one of the most significant current discussions due to the cost accompanying treatment, production loss, and work absenteeism [14-16]. Thus, it has become one of the most serious challenges in occupational health for reducing the financial impacts of health-related productivity and labor costs among office workers as a worthwhile business consideration [17].

Neck or shoulder pain symptoms appear to intensify since office workers with UCS generally sit with curved postures, take prolonged constant muscle activity, and perform repetitive job tasks $[18,19]$. Pain is considered as the strongest stimulus to central motor programming, which can alter electromyography (EMG) patterns in functional tasks since it has an inhibitory effect on muscle activation [20]. Some clinical studies confirmed that the tenderness of muscles is considered the most common type of neck or shoulder pain in office workers [19, 21, 22].
Due to the relationship between neck or shoulder pain and muscle tenderness, some studies reported that computer workers with neck and shoulder pain might have trapezius myalgia, tension neck syndrome, and cervicalgia [22, 23]. Thus, the majority of the office workers with frequent pain in shoulder and neck experienced tenderness of the upper trapezius muscle [23]. Further, Pietropaoli et al. reported higher EMG activity by more muscle tenderness scores when a general correlation was observed between muscle tenderness and EMG values [24].

Thus, individuals with insidious-onset cervical pain demonstrate poor postural stability more and significantly increased EMG levels in the SCM activity, respectively $[25,26]$.

Furthermore, due to the affected regions of painful UCS and alteration in muscle activation around the scapula and neck, EMG can be used as a reliable tool to validate the assessment of LT, MT, and SA activity decrease as well as UT activity increase [27-29].

Among office workers, postural changes and movement patterns in the scapula refer to the UCS including postural malalignments and altered muscle activity associated with workability and sickness absence [30]. Such conditions may play an important role in the development of neck and shoulder pain, which can be measured with electromyography as far as physiological measurement is concerned [31]. Meanwhile, balancing and restoring muscle activity by maintaining the alignment (upright body position) can reduce chronic neck pain and induce a more relaxed muscle activity pattern during work [32]. Due to the study population and WRMS Ds impacts containing workability and sickness absence, it is evident the importance of managing UCS symptoms along with monitoring muscle activity to decrease the incidence of subsequent impairments [33].

Then, knowledge is highly required regarding effective interventions for relieving WMSD symptoms and preventing the related consequences such as pain, work disability, and sickness absence [34]. In this regard, some studies reported statistically significant positive effects for improving office workers' workability by increasing physical activities [35]. Additionally, the results of some studies demonstrated that exercise has positive effects on health-related productivity loss and sickness absenteeism among office workers with neck pain in the longer term [36]. In addition, Seeberg et al. found a relationship between forward head posture (FHP) improvement and musculoskeletal pain after therapeutic exercises [34]. Further, the results of some studies indicated that exercises specific to the involved muscles restored malalignment and increased the ability to keep an upright cervical posture during work, as well as improved pain, disability, and the quality of life among 
office workers $[37,38]$. On the other hand, considering that different mechanisms may contribute to abnormal scapular movements, pain, abnormal thoracic posture, and imbalance muscle strength or activation [39], an exercise program can improve neck pain displaying positive and significant alterations in the forward head and protracted shoulder posture, disability, and the timing of superficial neck muscle activation [40, 41]. Finally, some positive effects of exercise interventions are presented for improving postural malalignments based on the majority of studies. However, both the neural and muscular components should be considered to accomplish the best performance [42-45].

Although previous studies have revealed the hopeful results of exercise interventions among different occupational groups, the question that remains is whether such interventions should be implemented under supervision or in the workplace $[34,46]$. The performance of worksite exercises in a group may be more motivating for some employees regarding increasing adherence although various barriers exist in this respect during working hours, which may be costly for employers regarding spending time and facilities [46]. Furthermore, although previous literature has demonstrated the positive efficacy of both supervised and unsupervised exercise programs, contradictory results are present about whether supervised or unsupervised exercise is more effective [47-49]. Several studies have simultaneously addressed all the involving factors related to UCS by applying exercise therapy. However, scarce research has focused on some separate areas of the upper body including the neck or shoulder among office workers [19, 40, 43, 50-53]. According to Hall et al. [54], the world is currently experiencing an extraordinary, life-altering challenge due to social distancing and home quarantine recommended by the World Health Organization to minimize the speed of the coronavirus disease (COVID19). Outdoor physical activities have been postponed in different cases $[55,56]$ since it is difficult to precisely predict when the COVID-19 pandemic diminishes and communities can return to normal function [57]. Accordingly, online-guided physical activities at home may be a way forward. Thus, studying the effect of workplace versus online-supervised exercises among office workers suffering from WMSDs including UCS is relevant.

\section{Objectives}

Given the explanations mentioned earlier, the present study seeks to evaluate the effect of workplace-based versus online-supervised home-based corrective exercises containing NSP and sick leave due to NSP as the primary objectives.

The secondary objectives include workability, alignment (i.e., neck, shoulder, and thoracic spine angles), and assessing the surface EMG of designated muscles including UT, MT, LT, SCM, and SA among office workers with UCS.

\section{Method \\ Study design}

A parallel-group randomized control trial with a pretestposttest design is used for the present study. Additionally, the selected subjects are randomly assigned to three groups including two interventions (i.e., onlinesupervised exercise and workplace exercise receiving 8 weeks of intervention) and a control group with no intervention performing routine activities. In addition, baseline assessments are organized at the Sports Science and Health Laboratory at Shahid Beheshti University, Tehran, Iran, and are repeated after 8 weeks of intervention. The procedure and flow diagram are shown in Table 1 and Fig. 1, respectively. The procedure is followed according to the SPIRIT ${ }^{1}$ guidelines to ensure the apparent and standardized reporting of the trial.

\section{Ethical considerations}

Before commencing the study, the procedure including assessments is explained to the subjects, and they are requested to complete and sign an informed consent form. Ethical clearance No. IR.SBU.REC.1399.036 dated 20 June 2020 was issued by the Ethics Committee on the Research at Shahid Beheshti University, Tehran, Iran. Further, IRCT No. IRCT20200729048249N1 dated 5 October 2020 was approved by the Iranian Registry of Clinical Trials (https://en.irct.ir/user/trial/49992/view). Furthermore, deviations from the present protocol are clearly described in the main article with the results of the trial.

\section{Subjects and eligibility criteria}

The corrective exercise specialist (Ph.D.) primarily screens the subjects recruited through invitation letters from private and public organizations in Tehran, Iran, for three main UCS features. Since the presence of scapular dyskinesia may indicate the lack of neuromuscular control, including muscle activation and timing thus, the related tests are performed to evaluate the position and rhythm of the scapula, which plays a significant role in facilitating the upper extremity function among office workers [58-60]. Further, due to any postural alteration influencing the muscle activity, muscle length and muscle strength tests are implemented for UT and pectoral muscles and MT, LT, and deep cervical flexor, respectively [61].

Inclusion criteria for the trial must comply with office workers between 30 and 45 years using a computer or

\footnotetext{
${ }^{1}$ Standard Protocol Items: Recommendations for Interventional Trials
} 


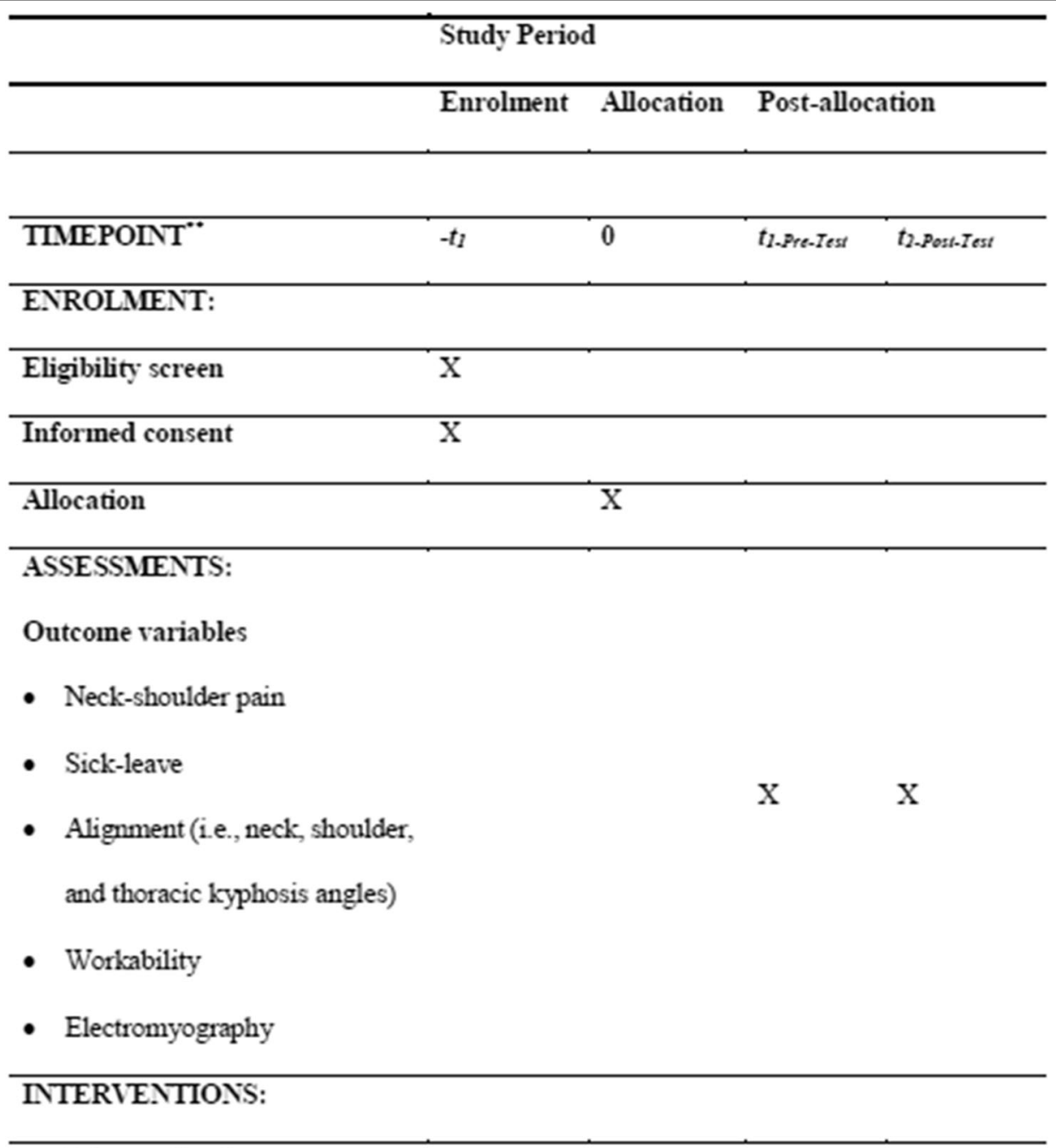

- Intervention l:

Online-supervised exercises

- Intervention 2:

Worlplace exercises

- Intervention 3:

Control

lab-tops most commonly during the working day (about $30 \mathrm{~h}$ per week) with at least 5 years of experience [17, $62]$. Having alignment alteration includes forward head $\left(\geq 45^{\circ}\right)$, round shoulder $\left(\geq 52^{\circ}\right)$, and round back $\left(\geq 42^{\circ}\right)$ according to previous studies [63, 64]. Marking pain intensity score visual analog scale (VAS) $\geq 3$ in neck and shoulder $[17,58,65]$.

Concerning exclusion criteria, those are ineligible if pregnant during the study process, having surgery on the upper extremities during the past year, unable to 


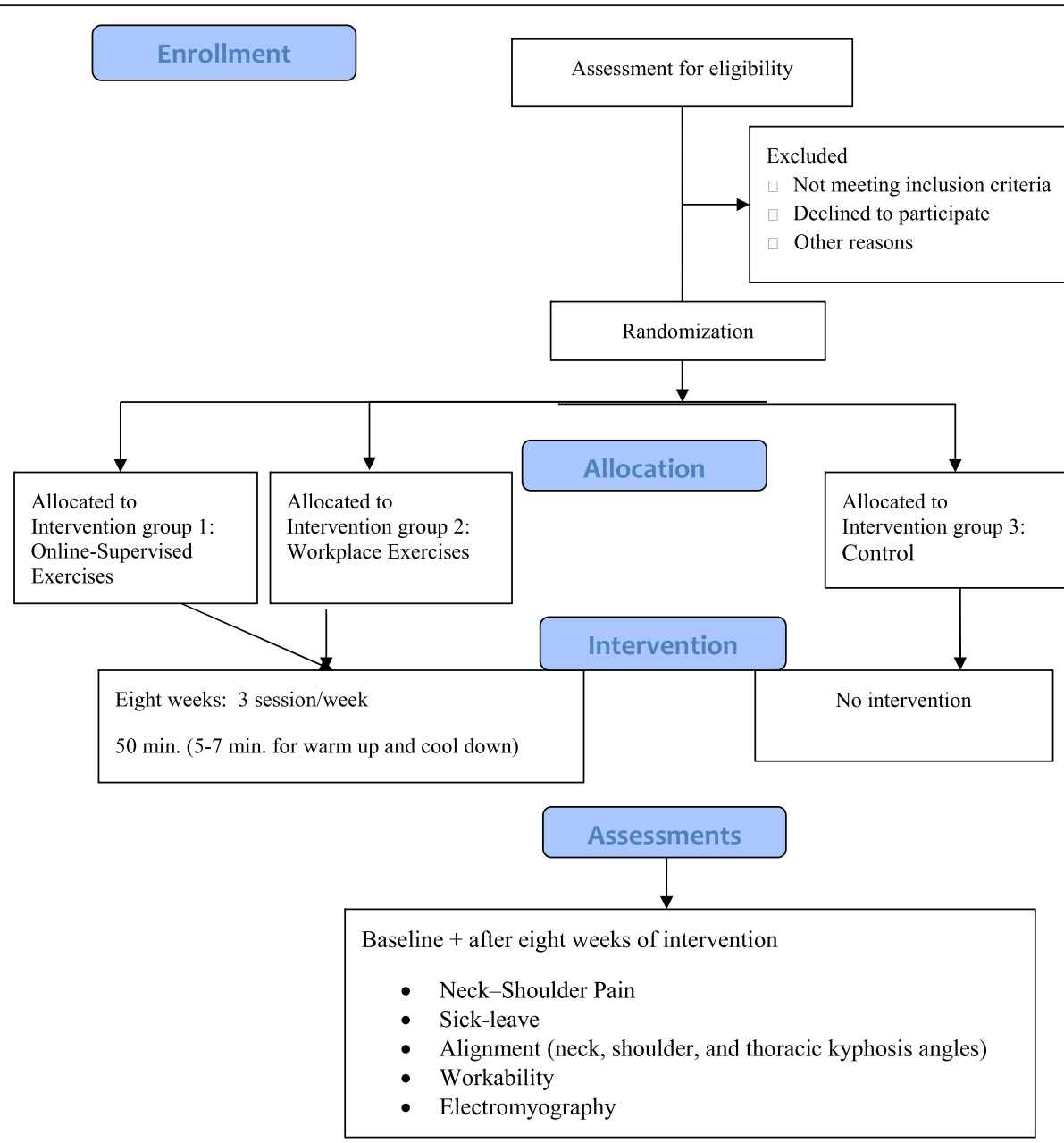

Fig. 1 Study flowchart

perform exercise due to any medical conditions, and being in weight out of the normal range $(18 \geq \mathrm{BMI} \geq 25)$.

Drop out criteria are considered if the subjects attend no post-tests, lose three sequential intervention sessions, and any factors that may affect the study results.

However, the subjects are allowed to discontinue the study at any stage [66]. At the first encounter at baseline, the researchers are asked for permission to contact them in the case of study discontinuation. Accordingly, performing an accurate intention-to-treat analysis of the primary result is possible.

\section{Randomization}

The subjects will be randomized to one of the two treatments and control groups including workplace exercise, online-supervised exercise, and control using https:// www.sealedenvelope.com. Randomization will be performed as block randomization with a 1:1 allocation. A sufficient number of the subjects will be recruited according to the sample size calculation to minimize random error. Meanwhile, to ensure the allocation concealment, the randomization code will not be released until the subject has been recruited into the trial, which occurs after all baseline measurements. Therefore, randomization will be performed through a computergenerated sequence for allocation concealment, including concealed, sequentially numbered, sealed, and opaque envelopes. A card inside indicates the allocated group to each subject [67].

The trial investigator will implement the various stages of the randomization process and enrollment and assign the subjects to interventions. The SBU professor assistant will supervise all the procedures implemented by the investigator, including the sequence generation process and allocation concealment mechanism during the study process to ensure that the assignment schedule is unpredictable and locked away from even the person who generated it.

The trial process is not independent of the investigators. The professor assistant (correspondent author) from SBU frequently supervises the procedures for auditing trial conducting a periodic independent review 
of core trial processes and documents. Auditing contains the participant enrolment, consent, eligibility, and allocation to study groups, adherence to trial interventions and policies to protect participants, including reporting of harms and completeness, accuracy, and timeliness of data collection.

A formal amendment to the protocol will be agreed upon by the Iranian Registry of Clinical Trials (IRCT), including any modifications to the protocol which may impact the conduct of the study, a potential benefit of the subjects, or may affect their safety, including changes of study objectives, study design, study population, sample sizes, study procedures, or significant administrative aspects. Meanwhile, the Ethics Committee on the Research will approve such an amendment at SBU, Tehran, Iran. The trial investigators are responsible for the decision to amend the protocol.

\section{Intervention}

As illustrated in Figs. 2 and 3, an 8-week corrective exercises protocol is taken by two intervention groups considering the UCS features such as alignment, muscle activity, and movement pattern simultaneously. The exercise program is performed three days per week to achieve the best results. Each session lasts nearly $50 \mathrm{~min}$, initiating by $5-7 \mathrm{~min}$ of warm-ups and finishing by cooldown, respectively [59]. In addition, the exercises are initiated by three repetitions holding for $10 \mathrm{~s}$ using the Borg scale [68] and progress to six repetitions, holding for $25 \mathrm{~s}$ based on overload principles and individual characteristics $[59,61]$. If reporting pain during the exercise performance, the subjects can discontinue and rest until pain relief, while moderating the exercises accordingly. A qualified corrective exercise instructor supervises the exercise programs of both intervention groups. The online-supervised group includes up to four subjects. Each session is remotely performed and supervised three times a week for 8 weeks in their home environment using real-time desktop videoconferencing software (https://meet.jit.si/) via a laptop computer. Accordingly, subjects can have contact and talk with both the instructor and the other subjects [62]. The workplace group performs all sessions in the worksite without daily face-to-face supervision, although supervision is conducted using diary and telephone interviews. Further, each participant in this group is provided with a detailed written exercise and pictorial descriptions to enhance exercise performance. However, the corrective exercise expert is present once a week during the exercise sessions to provide input and evaluate the progress and ensure that all subjects are exercising safely and correctly [49]. It is noteworthy that the corrective exercises protocol is expected to prevent the undesired lack of scapula stabilization on the thorax diminish neck and shoulder pain. Individuals with shoulder pain have excessive upper trapezius activation and decreased and/or delayed activation of the LT, MT, and SA [66]. Thus, exercises specifically targeting the trapezius and SA muscles are commonly incorporated into rehabilitation programs to optimize the scapular position and motion [69]. Recent studies indicated that the specific training of the neck muscles, such as strengthening deep cervical flexor muscles, could reduce neck pain and improve $\mathrm{SCM}$ endurance, which is effective in correcting head and shoulder postures $[68,70]$. Therefore, these exercises are recommended to improve the function of muscles in the neck, shoulder, and thoracic for several painful conditions due to their reduced or altered activation. At the follow-up, subjects are asked whether they have experienced any injuries or other adverse events during the training sessions.

The detailed exercise program is available for administration by two interventions groups in Figs. 2 and 3.

\section{Outcome measures}

Before randomization and at baseline, all assessments are performed and repeated after the intervention. NSP and sick leave due to pain are considered as the primary outcome variables, followed by the alignment, workability, and electromyography (EMG) activities of the selected muscles as the secondary variables. In the first part of the questionnaire, the subjects are asked to insert their demographic and social status including gender, age, weight, and height (body mass index $=\mathrm{kg} / \mathrm{m}^{2}$ ), work hour/week, years of experience, education level, and marital status [71].

\section{NSP intensity}

To determine NSP intensity, the subjects are asked through a questionnaire to mark a vertical line on the VAS line at the point which represents their pain intensity in each area (i.e., head, neck, shoulder, and upper back) on a scale ranging from 0 to 10 representing no pain and severe, respectively $[71,72]$.

\section{Workability and sick leave due to pain}

Workability is self-assessed using the related questionnaires by a single validated item from the workability index $[73,74]$. The subjects respond to one question as to how they rate their current workability according to their capabilities to meet the mental and physical demands of their job, which can still perform in two years. The response scores range from 0 to 10 , indicating inability to work and workability with a cut-off point score of $\leq 7$ implying poor workability, respectively [75]. In addition, sick leave due to pain is evaluated using a single item from the validated Outcome Evaluation Questionnaire to obtain data on the number of absence days 


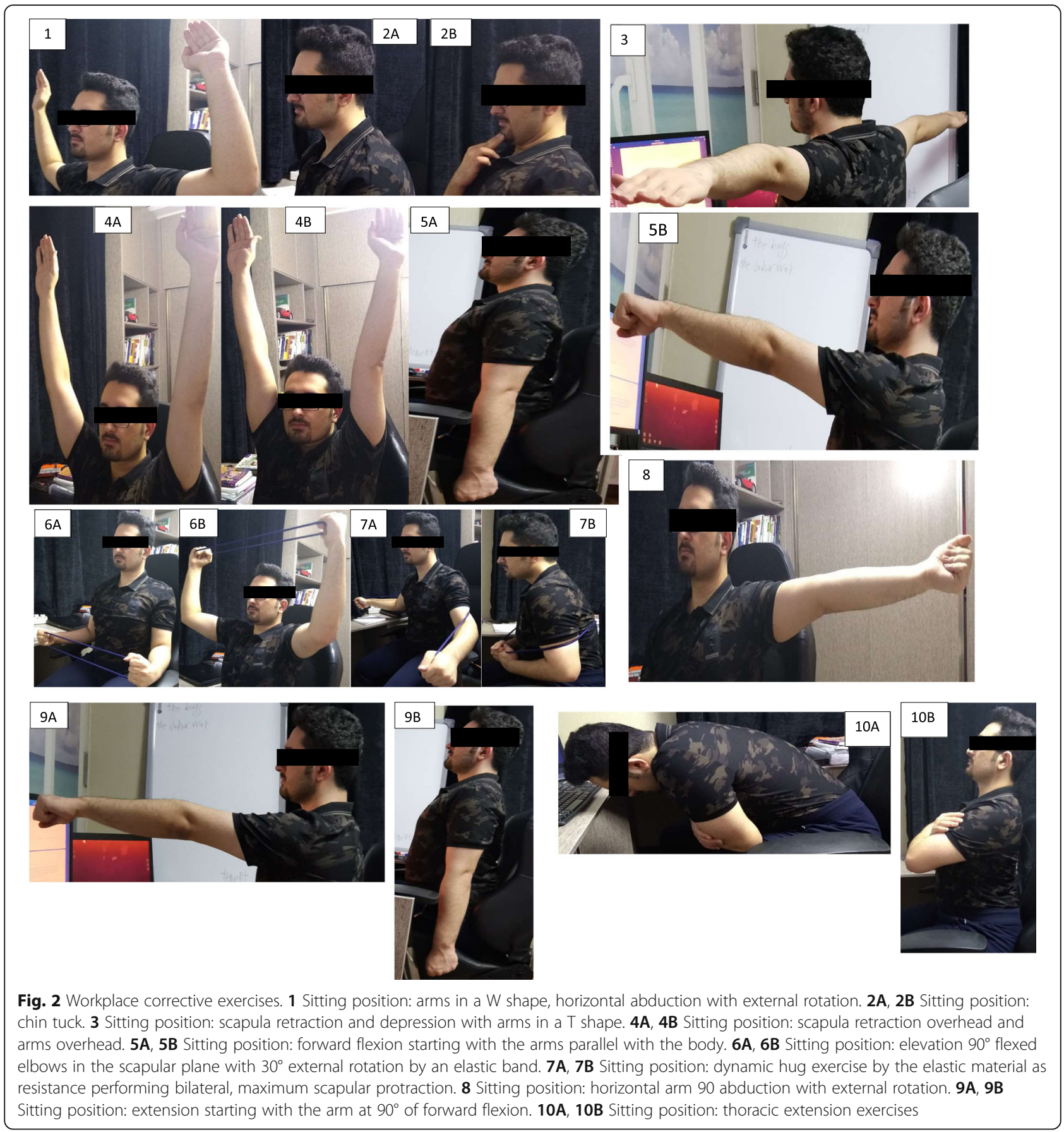

from work due to pain in muscles or joints within the past month, and response categories ranged from 0 to 31 days [76]. Based on a recent meta-analysis, selfreported sick leave demonstrates good reliability and validity against the records [77].

\section{Alignment}

To determine the angles for forward head and round shoulder postures, visible landmarks are placed on the ear tragus, the acromion process of the scapula, and the neck seventh vertebra process, as well as the 12th dorsal vertebra of the spinous for measuring the kyphosis angle, respectively [78]. Further, photogrammetry is utilized, asking the subjects to stand laterally and comfortably with bare feet on the flat floor while looking forward. A digital camera is fixed at a distance of 265 centimeters from the subjects, and then three photos are taken from the lateral view [79]. Furthermore, the angles are identified using AutoCAD software (version 2020) connecting a vertical line from the tragus to $\mathrm{C} 7$ for determining 

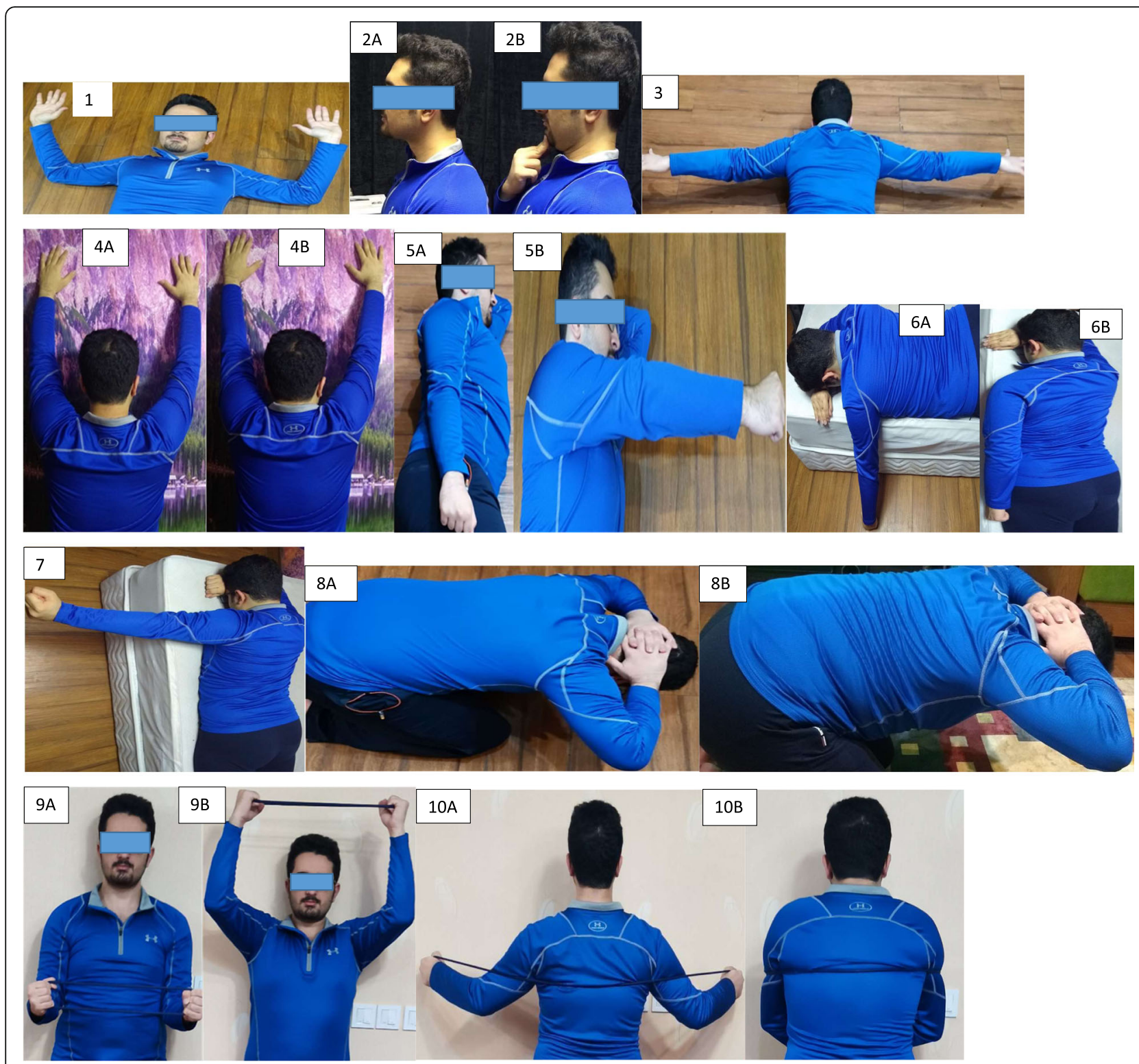

Fig. 3 Online-supervised corrective exercises. 1 Supine position: arms in a W shape and horizontal abduction with external rotation. 2A, 2B Sitting position: chin tuck. $\mathbf{3}$ Prone position: scapula retraction and depression with arms in a T shape. $\mathbf{4 A}, \mathbf{4 B}$ Standing position: scapula retraction overhead and arms overhead. 5A, 5B Side-lying position: forward flexion starting with the arms parallel with the body. 6A, 6B Prone position: extension starting with the arm at $90^{\circ}$ of forward flexion. $\mathbf{7}$ Prone position: horizontal arm 90 abduction with external rotation. $\mathbf{8 A}, \mathbf{8 B}$ Sitting position: thoracic extension exercise. $\mathbf{9 A}, \mathbf{9 B}$ Standing position: Elevation $90^{\circ}$ flexed elbows in the scapular plane with $30^{\circ}$ external rotation by the elastic band. 10A, 10B Standing position: dynamic hug exercise by the elastic material as resistance performing bilateral, maximum scapular protraction

forward head and continuing to the acromion process for displaying the rounded shoulder angles. To identify the thoracic kyphosis angle, C7 and T12 markers are considered as the starting and ending points of the arch. Previous research indicted the photogrammetry intrarater and interrater reliability ICC $0.98-0.99$ and ICC 0.91-0.99 respectively [78, 80-82]. Finally, the mean of three measurements is considered as the alignment angle.

\section{EMG}

The onset timing and amplitude for the dominant side of the selected muscles (i.e., UT, MT, LT, SCM, and SA) are recorded using EMG, and Matlab software is applied for data analysis [83]. After preparing the skin, electrodes are placed according to the European protocol of SENIAM ${ }^{2}$, and then the reference electrode for each muscle is

\footnotetext{
${ }^{2}$ Surface EMG for non-invasive assessment of muscles
} 
attached to the nearest bony site of the muscle. Additionally, a maximum voluntary isolated contraction (MVIC) is used to normalize and standardize the data by the root of the mean square (RMS). In addition, the subjects are requested to elevate their hand $30^{\circ}$ in the scapular plate without any resistance in three phases (i.e., isometric, concentric, and centric) five times with a 3-s break within each repetition. Then, the mean RMS is calculated based on three of five repetitions, followed by divining the mean RMS by the MVIC value multiplied by 100 to obtain the percentage of muscle activity [84]. The reliability of this method was observed within-day (0.85-0.99) and between-day (0.68-0.93) intraclass correlation coefficient for normalized RMS activity and within-day (0.94 ) and between-day (0.80) intraclass correlation coefficient for time broadness respectively $[85,86]$.

\section{Sample size}

Based on the results of the previous studies and a pilot study, 11 subjects are calculated for each group using G*Power software (version 3.0.10, Germany) with an alpha level of 0.05 , power $(1-\beta)$ of $80 \%$, and effect size of 0.66. It should be noted that the effect size was reported in the previous study that investigated the effects of corrective exercises on neck pain between the intervention and control groups [41]. However, to avoid the probability of losing the subjects during the research process, the number is considered 15 in every three groups $(N=45$ subjects).

\section{Statistical method and analysis}

Data are analyzed using IBM SPSS statistics software, version 24 for Windows, and descriptive statistics are applied to describe the variables considering sig. $\leq 0.05$. Further, data normality is reported based on the Shapiro-Wilk test.

A 3 (group) $\times 2$ (time) mixed-model repeatedmeasures ANOVA is used to compare all values from the pre-test to each point of the time within each group. Furthermore, the mixed-model repeated-measures ANOVA is applied to analyze within-group changes. Additionally, Bonferroni's post hoc test for indicating the significance is utilized for any significant difference, and one-way ANCOVA is employed to compare the groups in the post-test with each pre-test value as a covariate. In addition, the effect size is calculated for the magnitude of the difference using the partial $\eta 2$ method as small $(0.01 \leq \eta 2<0.06)$, medium $(0.06 \leq \eta 2<0.14)$, or large $(\eta 2 \geq 0.14)$. It should be noted that interim analyses were not planned in the present study.

\section{Discussion}

The present randomized control trial is conducted to assess the effect of workplace versus online-supervised corrective exercise interventions among 45 office workers suffering from UCS. The workplace exercise group receives an intervention without the direct supervision of an expert while another group performs the exercise under direct online supervision. These interventions are expected to improve and reduce UCS symptoms containing postural malalignment and imbalance muscles after eight weeks of corrective exercises. Further, it is estimated that the corrective exercises protocol leads to pain relief and an increase in workability in the worksites. Furthermore, the findings may be applied in various workplaces as evidence for those large populations of office workers involving WMSDs where employers can benefit from the actions by decreasing the related costs and side effects (e.g., work disability, productivity loss, time expense, social insurance, work absenteeism, and treatment costs, respectively). In this regard, most studies have only evaluated MSDs in different worksites including pain and work disability concentrating on a separate area (the neck or shoulder) or some specific muscles exclusively. On the other hand, a limited number of studies have considered the associations between malalignment, muscle imbalances, pain, and work disability among office works as a set of disorders named "UCS". Thus, the results of the present study may lead to the adherence and work performance of office workers who are subject to WMSDs and other individuals with UCS symptoms. Finally, the findings are predicted to elaborate on the effect of workplace exercises with indirect supervision versus direct onlinesupervision exercises after eight weeks of intervention.

\section{Trial status}

The present trial was registered under No. IRCT20200729048249N1 dated 5 October 2020 and the protocol version No. 49992. At present, the study is in the stage of subject enrollment, and recruitment is expected to begin on 2020.12.20 and complete by 2021.06.20.

\section{Abbreviations \\ MSDs: Musculoskeletal disorders; UCS: Upper crossed syndrome; NSP: Neck- shoulder pain; UT, MT, and LT: Upper, middle, and lower trapezius; \\ SCM: Sternocleidomastoid; SA: Serratus anterior; WNSDs: Work-related neck- shoulder disorders; EMG: Electromyography; FHP: Forward head posture; VAS: Visual Analogue Scale; MVIC: Maximum voluntary isolated contraction; RMS: Root mean square}

\section{Acknowledgements \\ We thank all the authors for their assistance during conducting the process of this study.}

\section{Authors' contributions}

Zohreh Yaghoubitajani (ZY) and Mehdi Gheitasi (MG) conceived the idea and designed the project. In addition, ZY performed the clinical examination and data collection. Further, MG and Mohammad Bayattork participated in the methodologically development and design of the statistical analysis.

Furthermore, Lars Louis Andersen contributed to the comments that greatly 
improved the manuscript. Finally, all authors contributed to the refinement of the study protocol and approved the final manuscript.

\section{Funding}

The authors report no conflicts of interest and no sources of funding.

\section{Availability of data and materials}

The researchers interested in using the final dataset for scientific purposes may contact the corresponding author.

\section{Declarations}

\section{Ethics approval and consent to participate}

The ethical clearance No. IR.SBU.REC.1399.036 dated 20 June 2020 was issued by the Ethics Committee on Research at Shahid Beheshti University, Tehran, Iran. Before study initiation, all subjects are requested to complete and sign a written consent form.

\section{Consent for publication}

The required permission for publishing subjects' photos in the manuscript was approved by written informed consent.

\section{Competing interests}

The present study received no specific grant from funding agencies in the public, commercial, or not-for-profit sectors. In addition, there are no sponsors and competing interests for the present protocol.

\section{Author details}

'Department of Health and Sports Rehabilitation, Faculty of Sports Science and Health, Shahid Beheshti University, Tehran, Iran. ${ }^{2}$ Sport Sciences and Physical Education, Faculty of Humanities Science, University of Hormozgan, Bandar Abbas, Iran. ${ }^{3}$ National Research Centre for the Working Environment, Copenhagen, Denmark. ${ }^{4}$ Sport Sciences, Department of Health Science and Technology, Aalborg University, 9220 Aalborg, Denmark.

Received: 12 April 2021 Accepted: 24 November 2021

Published online: 11 December 2021

\section{References}

1. Buckle PW, Devereux JJ. The nature of work-related neck and upper limb musculoskeletal disorders. Appl Ergon. 2002;33(3):207-17. https://doi.org/1 0.1016/S0003-6870(02)00014-5.

2. So BC, Szeto GP, Lau RW, Dai J, Tsang SM. Effects of ergomotor intervention on improving occupational health in workers with work-related neckshoulder pain. Int J Environ Res Public Health. 2019;16(24):5005. https://doi. org/10.3390/ijerph16245005.

3. Caneiro JP, O'Sullivan P, Burnett A, Barach A, O'Neil D, Tveit O, et al. The influence of different sitting postures on head/neck posture and muscle activity. Man Ther. 2010;15(1):54-60. https://doi.org/10.1016/j.math.2009.06.002.

4. Page P. Shoulder muscle imbalance and subacromial impingement syndrome in overhead athletes. Int J Sports Phys Ther. 2011;6(1):51.

5. Page P. Cervicogenic headaches: an evidence-led approach to clinical management. Int J Sports Phys Ther. 2011;6(3):254-66.

6. Luttmann A, Jäger M, Griefahn B, Caffier G, Liebers F. World Health Organization. Preventing musculoskeletal disorders in the workplace. Geneva: World Health Organization; 2003. https:/apps.who.int/iris/handle/10665/42651.

7. Robertson MM, Ciriello VM, Garabet AM. Office ergonomics training and a sit-stand workstation: effects on musculoskeletal and visual symptoms and performance of office workers. Appl Ergon. 2013;44(1):73-85. https://doi. org/10.1016/j.apergo.2012.05.001.

8. Andersen JH, Fallentin N, Thomsen JF, Mikkelsen S. Risk factors for neck and upper extremity disorders among computers users and the effect of interventions: an overview of systematic reviews. PloS One. 2011:6(5): e19691. https://doi.org/10.1371/journal.pone.0019691.

9. Ketkar GN, Malaiappan S. Knowledge attitude and practice of ergonomics and musculoskeletal disorders as an occupational hazard among periodontists in India-a questionnaire based survey. J Pharm Res Int. 2020: 162-83. https://doi.org/10.9734/jpri/2020/v32i2030739.

10. Côté P, Boyle E, Shearer HM, Stupar M, Jacobs C, Cassidy JD, et al. Is a government-regulated rehabilitation guideline more effective than general practitioner education or preferred-provider rehabilitation in promoting recovery from acute whiplash-associated disorders? A pragmatic randomised controlled trial. BMJ Open. 2019;9(1):e021283.

11. Hallman DM, Holtermann A, Dencker-Larsen S, Jørgensen MB, Rasmussen CDN. Are trajectories of neck-shoulder pain associated with sick leave and work ability in workers? A 1-year prospective study. BMJ Open. 2019;9(3): e022006. https://doi.org/10.1136/bmjopen-2018-022006.

12. Andersen LL, Mortensen OS, Hansen JV, Burr H. A prospective cohort study on severe pain as a risk factor for long-term sickness absence in blue-and white-collar workers. Occup Environ Med. 2011;68(8):590-2. https://doi.org/1 0.1136/oem.2010.056259.

13. Dianat I, Bazazan A, Azad MAS, Salimi SS. Work-related physical, psychosocial and individual factors associated with musculoskeletal symptoms among surgeons: Implications for ergonomic interventions. Appl Ergon. 2018;67:115-24. https://doi.org/10.1016/j.apergo.2017.09.011.

14. Thacker D, Jameson J, Baker J, Divine J, Unfried A. Management of upper cross syndrome through the use of active release technique and prescribed exercises. Logan College of Chiropractic; 2011. https://www.logan.edu/mm/ files/LRC/Senior-Research/2011-Apr-03.pdf

15. Daneshmandi $\mathrm{H}$, Choobineh $\mathrm{A}$, Ghaem $\mathrm{H}$, Alhamd $\mathrm{M}$, Fakherpour $\mathrm{A}$. The effect of musculoskeletal problems on fatigue and productivity of office personnel: a cross-sectional study. J Prev Med Hyg. 2017:58(3):E252.

16. Sundstrup E, Seeberg KGV, Bengtsen E, Andersen LL. A systematic review of workplace interventions to rehabilitate musculoskeletal disorders among employees with physical demanding work. J Occup Rehabil. 2020;30(4):125. https://doi.org/10.1007/s10926-020-09879-x.

17. Ting JZR, Chen $X$, Johnston V. Workplace-based exercise intervention improves work ability in office workers: a cluster randomised controlled trial. Int J Environ Res Public Health. 2019;16(15):2633. https://doi.org/10.3390/ ijerph16152633.

18. Gu S-Y, Hwangbo G, Lee J-H. Relationship between position sense and reposition errors according to the degree of upper crossed syndrome. J Phys Ther Sci. 2016;28(2):438-41. https://doi.org/10.1589/jpts.28.438.

19. Brandt M, Sundstrup E, Jakobsen MD, Jay K, Colado JC, Wang Y, et al. Association between neck/shoulder pain and trapezius muscle tenderness in office workers. Pain Res Treat. 2014;2014:1-4. https://doi.org/10.1155/2014/352735.

20. Madeleine $P$, Lundager B, Voigt M, Arendt-Nielsen L. Shoulder muscle coordination during chronic and acute experimental neck-shoulder pain. An occupational pain study. Eur J Appl Physiol Occup Physiol. 1999;79(2):12740. https://doi.org/10.1007/s004210050486.

21. Buckle P. Ergonomics and musculoskeletal disorders: overview. Occup Med. 2005;55(3):164-7. https://doi.org/10.1093/occmed/kqi081.

22. Juul-Kristensen B, Kadefors R, Hansen K, Byström P, Sandsjö L, Sjøgaard G. Clinical signs and physical function in neck and upper extremities among elderly female computer users: the NEW study. Eur J Appl Physiol. 2006; 96(2):136-45. https://doi.org/10.1007/s00421-004-1220-4.

23. Andersen LL, Hansen K, Mortensen OS, Zebis MK. Prevalence and anatomical location of muscle tenderness in adults with nonspecific neck shoulder pain. BMC Musculoskelet Disord. 2011;12(1):1-8. https://doi.org/1 0.1186/1471-2474-12-169.

24. Pietropaoli D, Ortu E, Giannoni M, Cattaneo R, Mummolo A, Monaco A. Alterations in surface electromyography are associated with subjective masticatory muscle pain. Pain Res Manag. 2019;2019:1-9. https://doi.org/1 0.1155/2019/6256179.

25. Jull G, Kristjansson E, Dall'Alba P. Impairment in the cervical flexors: a comparison of whiplash and insidious onset neck pain patients. Man Ther. 2004;9(2):89-94. https://doi.org/10.1016/S1356-689X(03)00086-9.

26. Sterling M. Whiplash-associated disorder: musculoskeletal pain and related clinical findings. J Man Manip Ther. 2011;19(4):194-200. https://doi.org/10.11 79/106698111X13129729551949.

27. Cricchio M, Frazer C. Scapulothoracic and scapulohumeral exercises: a narrative review of electromyographic studies. J Hand Ther. 2011;24(4):32234. https://doi.org/10.1016/j.jht.2011.06.001.

28. Arshadi R, Ghasemi GA, Samadi H. Effects of an 8-week selective corrective exercises program on electromyography activity of scapular and neck muscles in persons with upper crossed syndrome: randomized controlled trial. Phys Ther Sport. 2019;37:113-9. https://doi.org/10.1016/j.ptsp.2019.03.008.

29. Seidi F, Bayattork M, Minoonejad H, Andersen LL, Page P. Comprehensive corrective exercise program improves alignment, muscle activation and movement pattern of men with upper crossed syndrome: randomized controlled trial. Sci Rep. 2020;10(1):1-11. https://doi.org/10.1038/s41598-02077571-4. 
30. Loghmani A, Golshiri P, Zamani A, Kheirmand M, Jafari N. Musculoskeletal symptoms and job satisfaction among office-workers: a cross-sectional study from Iran. Acta Med Acad. 2013;42(1):46-54. https://doi.org/10.5644/a ma2006-124.70.

31. Lidegaard M, Jensen RB, Andersen CH, Zebis MK, Colado JC, Wang Y, et al. Effect of brief daily resistance training on occupational neck/shoulder muscle activity in office workers with chronic pain: randomized controlled trial. BioMed Res Int. 2013;2013:1-11. https://doi.org/10.1155/2013/262386.

32. Falla $D$, Jull $G$, Russell $T$, Vicenzino $B$, Hodges P. Effect of neck exercise on sitting posture in patients with chronic neck pain. Physical therapy. 2007; 87(4):408-17. https://doi.org/10.2522/ptj.20060009.

33. Lee $S$, Lee $Y$, Chung $Y$. Effect of changes in head postures during use of laptops on muscle activity of the neck and trunk. Phys Ther Rehabil Sci. 2017;6(1):33-8. https://doi.org/10.14474/ptrs.2017.6.1.33.

34. Seeberg KGV, Andersen LL, Bengtsen E, Sundstrup E. Effectiveness of workplace interventions in rehabilitating musculoskeletal disorders and preventing its consequences among workers with physical and sedentary employment: systematic review protocol. Syst Rev. 2019;8(1):1-7. https://doi. org/10.1186/s13643-019-1127-0

35. Lusa S, Punakallio A, Mänttäri S, Korkiakangas E, Oksa J, Oksanen T, et al. Interventions to promote work ability by increasing sedentary workers' physical activity at workplaces-A scoping review. Appl Ergon. 2020;82: 102962. https://doi.org/10.1016/j.apergo.2019.102962.

36. Pereira M, Comans T, Sjøgaard G, Straker L, Melloh M, O'leary S, et al. The impact of workplace ergonomics and neck-specific exercise versus ergonomics and health promotion interventions on office worker productivity: A cluster-randomized trial. Scand J Work Environ Health. 2019; 45(1):42-52. https://doi.org/10.5271/sjweh.3760.

37. Sheikhhoseini R, Shahrbanian S, Sayyadi P, O'Sullivan K. Effectiveness of therapeutic exercise on forward head posture: a systematic review and meta-analysis. J Manipul Physiol Ther. 2018;41(6):530-9. https//doi.org/10.1016/j.jmpt.2018.02.002.

38. Borisut $S$, Vongsirinavarat M, Vachalathiti R, Sakulsriprasert P. Effects of strength and endurance training of superficial and deep neck muscles on muscle activities and pain levels of females with chronic neck pain. J Phys Ther Sci. 2013;25(9):1157-62. https://doi.org/10.1589/jpts.25.1157.

39. Camargo PR, Neumann DA. Kinesiologic considerations for targeting activation of scapulothoracic muscles-part 2: trapezius. Braz J Phys Ther. 2019;23(6):467-75. https://doi.org/10.1016/j.bjpt.2019.01.011.

40. Welch A, Healy G, Straker L, Comans T, O'Leary S, Melloh M, et al. Process evaluation of a workplace-based health promotion and exercise clusterrandomised trial to increase productivity and reduce neck pain in office workers: A RE-AIM approach. BMC Public Health. 2020;20(1):180. https://doi. org/10.1186/s12889-020-8208-9

41. Mehri A, Letafatkar A, Khosrokiani Z. Effects of corrective exercises on posture, pain, and muscle activation of patients with chronic neck pain exposed to anterior-posterior perturbation. J Manipul Physiol Ther. 2020; 43(4):311-24. https://doi.org/10.1016/j.jmpt.2018.11.032.

42. Hotta GH, Santos AL, McQuade KJ, de Oliveira AS. Scapular-focused exercise treatment protocol for shoulder impingement symptoms: three-dimensional scapular kinematics analysis. Clin Biomech. 2018;51:76-81. https://doi.org/1 0.1016/j.clinbiomech.2017.12.005.

43. Saeterbakken AH, Makrygiannis P, Stien N, Solstad TEJ, Shaw M, Andersen V, et al. Dose-response of resistance training for neck-and shoulder pain relief: a workplace intervention study. BMC Sports Sci Med Rehabil. 2020;12(1):1-8. https://doi.org/10.1186/s13102-020-0158-0.

44. Mehri A, Letafatkar A. Efficacy of corrective exercise intervention on forward head angle, pain and timing of superficial neck muscles activation during posterior-anterior perturbation in women with chronic neck pain. Majallah-i pizishki-i Danishgah-i Ulum-i Pizishki va Khadamat-i Bihdashti-i Darmani-i Tabriz. 2018;40(1):66-76.

45. Bayattork M, Sköld MB, Sundstrup E, Andersen LL. Exercise interventions to improve postural malalignments in head, neck, and trunk among adolescents, adults, and older people: systematic review of randomized controlled trials. J Exerc Rehabil. 2020;16(1):36-48. https://doi.org/10.12965/jer.2040034.017.

46. Jakobsen MD, Sundstrup E, Brandt M, Jay K, Aagaard P, Andersen LL. Effect of workplace-versus home-based physical exercise on musculoskeletal pain among healthcare workers: a cluster randomized controlled trial. Scand J Work Environ Health. 2015;41(2):153-63. https://doi.org/10.5271/sjweh.3479.

47. Fennell C, Peroutky K, Glickman E. Effects of supervised training compared to unsupervised training on physical activity, muscular endurance, and cardiovascular parameters. MOJ Orthop Rheumatol. 2016;5(5):00184.
48. Cox KL, Burke V, Gorely TJ, Beilin L, Puddey IB. Controlled comparison of retention and adherence in home-vs center-initiated exercise interventions in women ages 40-65 years: the SWEAT study (Sedentary Women Exercise Adherence Trial). Prev Med. 2003;36(1):17-29. https://doi.org/10.1006/pmed.2002.1134.

49. Stefanov T, Vekova A, Bonova I, Tzvetkov S, Kurktschiev D, Blüher M, et al. Effects of supervised vs non-supervised combined aerobic and resistance exercise programme on cardiometabolic risk factors. Cent Eur J Public Health. 2013;21(1):8-16. https://doi.org/10.21101/cejph.a3801.

50. Bau J-G, Chia T, Wei S-H, Li Y-H, Kuo F-C. Correlations of neck/shoulder perfusion characteristics and pain symptoms of the female office workers with sedentary lifestyle. PloS One. 2017;12(1):e0169318. https://doi.org/10.13 71/journal.pone.0169318.

51. Chen X, Coombes BK, Sjøgaard G, Jun D, O'Leary S, Johnston V. Workplacebased interventions for neck pain in office workers: systematic review and meta-analysis. Phys Ther. 2018;98(1):40-62. https://doi.org/10.1093/ptj/pzx101.

52. Louw S, Makwela S, Manas L, Meyer L, Terblanche D, Brink Y. Effectiveness of exercise in office workers with neck pain: A systematic review and metaanalysis. S Afr J Physiother. 2017;73(1):392

53. Heredia-Rizo AM, Petersen KK, Madeleine P, Arendt-Nielsen L. Clinical outcomes and central pain mechanisms are improved after upper trapezius eccentric training in female computer users with chronic neck/shoulder pain. Clin J Pain. 2019;35(1):65-76. https://doi.org/10.1097/AJP. 0000000000000656.

54. Hall G, Laddu DR, Phillips SA, Lavie CJ, Arena R. A tale of two pandemics: How will COVID-19 and global trends in physical inactivity and sedentary behavior affect one another? Prog Cardiovasc Dis. 2020;64:108-10.

55. Sañudo B, Fennell C, Sánchez-Oliver AJ. Objectively-assessed physical activity, sedentary behavior, smartphone use, and sleep patterns pre-and during-COVID-19 quarantine in young adults from Spain. Sustainability. 2020;12(15):5890. https://doi.org/10.3390/su12155890.

56. Hammami A, Harrabi B, Mohr M, Krustrup P. Physical activity and coronavirus disease 2019 (COVID-19): specific recommendations for homebased physical training. Manag Sport Leis. 2020:1-6. https://doi.org/10.1 080/23750472.2020.1757494.

57. Constandt B, Thibaut E, De Bosscher V, Scheerder J, Ricour M, Willem A. Exercising in times of lockdown: an analysis of the impact of COVID-19 on levels and patterns of exercise among adults in Belgium. Int J Environ Res Public Health. 2020;17(11):4144. https://doi.org/10.3390/ijerph17114144.

58. Marklund S, Mienna CS, Wahlström J, Englund E, Wiesinger B. Work ability and productivity among dentists: associations with musculoskeletal pain, stress, and sleep. Int Arch Occup Environ Health. 2020;93(2):271-8. https:// doi.org/10.1007/s00420-019-01478-5.

59. Sahrmann S. Movement system impairment syndromes of the extremities, cervical and thoracic spines-e-book. 1st Edition. Elsevier Health Sciences; 2010. p 54-84.

60. Katzman WB, Vittinghoff E, Kado DM, Schafer AL, Wong SS, Gladin A, et al. Study of hyperkyphosis, exercise and function (SHEAF) protocol of a randomized controlled trial of multimodal spine-strengthening exercise in older adults with hyperkyphosis. Phys Ther. 2016;96(3):371-81. https://doi. org/10.2522/ptj.20150171.

61. Falla $D$, Jull $G$, Hodges $P$, Vicenzino $B$. An endurance-strength training regime is effective in reducing myoelectric manifestations of cervical flexor muscle fatigue in females with chronic neck pain. Clin Neurophysiol. 2006; 117(4):828-37. https://doi.org/10.1016/j.clinph.2005.12.025.

62. Tsai LLY, McNamara RJ, Dennis SM, Moddel C, Alison JA, McKenzie DK, et al. Satisfaction and experience with a supervised home-based real-time videoconferencing telerehabilitation exercise program in people with chronic obstructive pulmonary disease (COPD). Int J Telerehabilitation. 2016; 8(2):27-38. https://doi.org/10.5195/ijt.2016.6213.

63. Tate AR, McClure $P$, Kareha $S$, Irwin D, Barbe MF. A clinical method for identifying scapular dyskinesis, part 2: validity. J Athl Train. 2009;44(2):16573. https://doi.org/10.4085/1062-6050-44.2.165.

64. Bayattork M, Seidi F, Minoonejad H, Andersen LL, Page P. The effectiveness of a comprehensive corrective exercises program and subsequent detraining on alignment, muscle activation, and movement pattern in men with upper crossed syndrome: protocol for a parallelgroup randomized controlled trial. Trials. 2020;21(1):1-10. https://doi. org/10.1186/s13063-020-4159-9.

65. Castro RRTd, Silveira JGd, Castro RRTd. Exercise training: a hero that can fight two pandemics at once. Int J Cardiovasc Sci 2020;33:284-287, 3, https://doi.org/10.36660/ijcs.20200083. 
66. Cools AM, Struyf F, De Mey K, Maenhout A, Castelein B, Cagnie B. Rehabilitation of scapular dyskinesis: from the office worker to the elite overhead athlete. Br J Sports Med. 2014;48(8):692-7. https://doi.org/10.1136/ bjsports-2013-092148.

67. Chan A-W, Tetzlaff JM, Gøtzsche PC, Altman DG, Mann H, Berlin JA, et al. SPIRIT 2013 explanation and elaboration: guidance for protocols of clinical trials. Bmj. 2013;346(jan08 15). https://doi.org/10.1136/bmj.e7586.

68. Moon J-H, Jung J-H, Hahm S-C, Jung K-S, Suh HR, H-y C. Effects of chin tuck exercise using neckline slimmer device on suprahyoid and sternocleidomastoid muscle activation in healthy adults. J Phys Ther Sci. 2018;30(3):454-6. https://doi.org/10.1589/jpts.30.454.

69. Neumann DA, Camargo PR. Kinesiologic considerations for targeting activation of scapulothoracic muscles-part 1: serratus anterior. Braz J Phys Ther. 2019;23(6):459-66. https://doi.org/10.1016/j.bjpt.2019.01.008.

70. Suvarnnato T, Puntumetakul R, Uthaikhup S, Boucaut R. Effect of specific deep cervical muscle exercises on functional disability, pain intensity, craniovertebral angle, and neck-muscle strength in chronic mechanical neck pain: a randomized controlled trial. J Pain Res. 2019;12:915-25. https://doi. org/10.2147/JPR.S190125

71. Gram B, Holtermann A, Bültmann U, Sjøgaard G, Søgaard K. Does an exercise intervention improving aerobic capacity among construction workers also improve musculoskeletal pain, work ability, productivity, perceived physical exertion, and sick leave?: a randomized controlled trial. J Occup Environ Med. 2012;54(12):1520-6. https://doi.org/10.1097/JOM.0b013 e318266484a.

72. Von Korff M, Ormel J, Keefe FJ, Dworkin SF. Grading the severity of chronic pain. Pain. 1992;50(2):133-49. https://doi.org/10.1016/0304-3959(92)90154-4.

73. Ahlstrom L, Grimby-Ekman A, Hagberg M, Dellve L. The work ability index and single-item question: associations with sick leave, symptoms, and health-a prospective study of women on long-term sick leave. Scand J Work Environ Health. 2010;36(5):404-12. https://doi.org/10.5271/sjweh.2917.

74. Tuomi K, Ilmarinen J, Jahkola A, Katajarinne L, Tulkki A. Work Ability Index. 2nd Edition (Vol. 19). Helsinki: Finnish Institute of Occupational Health; 1998.

75. Neupane S, Miranda H, Virtanen P, Siukola A, Nygård C-H. Multi-site pain and work ability among an industrial population. Occup Med. 2011;61(8): 563-9. https://doi.org/10.1093/occmed/kgr130.

76. Holtermann A, Hansen JV, Burr H, Søgaard K. Prognostic factors for longterm sickness absence among employees with neck-shoulder and low-back pain. Scand J Work Environ Health. 2010;36(1):34-41. https://doi.org/10.52 71/sjweh.2883.

77. Johns G, Miraglia M. The reliability, validity, and accuracy of self-reported absenteeism from work: A meta-analysis. J Occup Health Psychol. 2015; 20(1):1-14. https://doi.org/10.1037/a0037754

78. Karimian R, Rahnama N, Ghasemi G, Lenjannejadian S. Photogrammetric analysis of upper cross syndrome among teachers and the effects of National Academy of Sports Medicine exercises with ergonomic intervention on the syndrome. J Res Health Sci. 2019;19(3):e00450.

79. Harman K, Hubley-Kozey CL, Butler H. Effectiveness of an exercise program to improve forward head posture in normal adults: a randomized, controlled 10-week trial. J Man Manipul Ther. 2005;13(3):163-76. https://doi. org/10.1179/106698105790824888.

80. Gadotti IC, Armijo-Olivo S, Silveira A, Magee D. Reliability of the craniocervical posture assessment: visual and angular measurements using photographs and radiographs. J Man Manipul Ther. 2013;36(9):619-25. https://doi.org/10.1016/j.jmpt.2013.09.002.

81. Ruivo RM, Pezarat-Correia P, Carita Al. Intrarater and interrater reliability of photographic measurement of upper-body standing posture of adolescents. J Manipul Physiol Ther. 2015;38(1):74-80. https://doi.org/10.1016/j.jmpt.2 014.10.009.

82. Singla D, Veqar Z, Hussain ME. Photogrammetric assessment of upper body posture using postural angles: a literature review. J Chiropr Med. 2017;16(2): 131-8. https://doi.org/10.1016/j.jcm.2017.01.005.

83. Johnston V, Jull G, Souvlis T, Jimmieson NL. Neck movement and muscle activity characteristics in female office workers with neck pain. Spine. 2008; 33(5):555-63. https://doi.org/10.1097/BRS.0b013e3181657d0d.

84. Castelein B, Cools A, Parlevliet T, Cagnie B. Are chronic neck pain, scapular dyskinesis and altered scapulothoracic muscle activity interrelated?: A casecontrol study with surface and fine-wire EMG. J Electromyogr Kinesiol. 2016; 31:136-43. https://doi.org/10.1016/j.jelekin.2016.10.008.
85. Zandi S, Rajabi R, Mohseni-Bandpei M, Minoonejad H. Electromyographic analysis of shoulder girdle muscles in volleyball throw: a reliability study. Age [years]. 2018;20(1.94):19.00.

86. Derakhshani A, Letafatkar A, Khosrokiani Z. Comparing the effects of SUREE programs on people with scapular downward rotation syndrome: a randomized clinical trial. J Sport Rehabil. 2019;28(8):787-95. https://doi.org/1 0.1123/jsr.2018-0051.

\section{Publisher's Note}

Springer Nature remains neutral with regard to jurisdictional claims in published maps and institutional affiliations.
Ready to submit your research? Choose BMC and benefit from:

- fast, convenient online submission

- thorough peer review by experienced researchers in your field

- rapid publication on acceptance

- support for research data, including large and complex data types

- gold Open Access which fosters wider collaboration and increased citations

- maximum visibility for your research: over $100 \mathrm{M}$ website views per year

At BMC, research is always in progress.

Learn more biomedcentral.com/submissions 